\title{
Analisis Produk Hasil Kombinasi Proses Pengelasan dan Perlakuan Panas Aluminium 6061
}

\author{
Yunita Sari \\ Universitas Negeri Jakarta, Fakultas Teknik, Jurusan Teknik Mesin \\ Jalan Rawamangun Muka, Pulogadung, Jakarta Timur \\ E-mail: yunitasari@unj.ac.id / yunitasariunj@gmail.com
}

\begin{abstract}
Abstrak
Sering kali di industri suatu komponen atau struktur dari logam aluminium (aluminium alloys) harus mengalami proses manufaktur pengelasan (welding) sebagai salah satu metode penyambungan logam (metal joining) dan perlakuan panas (heat treatment) untuk memperoleh atau mengubah sifat tertentu dari logam tersebut, karena itu perlu dilakukan analisis terhadap kombinasi kedua proses tersebut. Penelitian ini bertujuan mengetahui pengaruh kombinasi pengelasan dan perlakuan panas terhadap sifat mekanik (mechanical properties) logam aluminium.
\end{abstract}

Material teknik yang digunakan adalah logam aluminium 6061, proses pengelasan yang dilakukan adalah tungsten inert gas (TIG welding) atau GTAW (Gas Tungsten Arc Welding), proses perlakuan panas yang dilakukan adalah aging (precipitation hardening/ strengthening), pengujian yang dilaksanakan adalah pengujian tarik (tensile/tension test) dan pengujian kekerasan (hardness test).

Kekuatan logam rata-rata setelah dilakukan proses pengelasan adalah $28,5 \mathrm{Kg} / \mathrm{mm}^{2}$ artinya logam ini mampu menahan beban hingga sebesar itu tanpa mengalami perpatahan (fracture), sedangkan kekuatan logam lasan setelah dilakukan proses perlakuan panas rata-rata meningkat menjadi $48,7 \mathrm{Kgf} / \mathrm{mm}^{2}$. Secara umum nilai kekerasan logam berbanding lurus dengan kekuatannya sehingga kekerasan logam lasan setelah dilakukan proses perlakuan panas juga meningkat. Kesimpulan yang diperoleh dari penelitian ini adalah bahwa proses perlakuan panas artificial aging pada hasil proses pengelasan logam aluminium secara umum akan meningkatkan sifat mekanik.

Kata Kunci: Pengelasan, Perlakuan Panas, Aluminium 6061

\section{Pendahuluan}

Logam aluminium umumnya diklasifikasikan menjadi dua kelompok yaitu yang dapat merespon perlakuan panas (heattreatable) dan yang tidak merespon perlakuan panas (non-heat-treatable). Logam aluminium yang dapat ditingkatkan kekuatan/kekerasannya dengan proses perlakuan panas adalah seri $2 \mathrm{xxx}, 6 \mathrm{xxx}$, dan $7 x x x$. Sedangkan logam aluminium yang memiliki kemampulasan (weldability) terbaik adalah aluminium 6061.

Kelompok elektroda tak terumpan menggunakan batang wolfram (tungsten) sebagai elektroda yang dapat menghasilkan busur listrik tanpa turut mencair, sedangkan kelompok elektroda terumpan sebagai elektrodanya digunakan kawat las. Kelompok elektroda tak terumpan biasanya menggunakan gas mulia atau gas inert sebagai pelindung sehingga nama kelompok pengelasan ini menjadi las TIG (tungsten inert gas). Kelompok elektroda tak terumpan masih dibagi lagi ke dalam dua jenis, yaitu jenis dengan logam pengisi (filler metal) dan jenis tanpa logam pengisi.

Sumber listrik yang digunakan untuk pengelasan TIG dapat berupa listrik DC atau listrik AC. Dalam hal listrik DC rangkaian listriknya bisa dengan polaritas lurus (straight polarity) dimana kutub positif dihubungkan dengan logam induk dan kutub negatif dengan elektroda, atau rangkaian sebaliknya yang disebut polaritas balik (reverse polarity). Dalam polaritas lurus, elektron bergerak dari elektroda dan menumbuk 
logam induk dengan kecepatan yang tinggi sehingga dapat terjadi penetrasi yang dalam. Karena pada elektroda tidak terjadi tumbukan elektron maka temperatur elektroda relatif tidak terlalu tinggi, sehingga dengan polaritas ini bisa digunakan arus yang besar. Selain itu terjadi proses ionisasi pada gas argon yang menyelubungi logam dan terbentuk ion-ion argon positif $\left(\mathrm{Ar}^{+}\right)$yang akan menumbuk logam dasar (base metal) dan dapat melepaskan lapisan oksida yang ada di permukaannnya.

Semua proses pengelasan dapat menghasilkan cacat pengelasan seperti inklusi, porositas, undercutting, pembekuan tidak sempurna, retak, dan penetrasi tak sempurna. Penyebab terjadinya cacat las tersebut dikarenakan oleh teknik pengelasan yang tidak baik, pemilihan parameter las yang tidak tepat, logam induk dan kawat las yang tidak tepat, serta tidak sesuainya pelindung yang digunakan. Inklusi merupakan cacat yang dijumpai pada logam las yang dihasilkan dari proses arc welding yang menggunakan fluks sebagai pelindung atmosfir. Cacat inklusi terbentuk karena adanya terak, oksida, atau sisa elektroda yang masuk ke deposit las. Adapun penyebab terjadinya inklusi antara lain adalah kecepatan pengelasan yang terlalu tinggi/rendah, kampuh terlalu lebar, arus terlalu rendah, konsumsi elektroda yang berlebih, kontak antara elektroda dengan benda kerja terlalu lama, dan komposisi fluks tidak sesuai. Porositas merupakan jenis cacat berupa lubang halus yang terjadi akibat adanya udara/gas yang terperangkap dalam deposit las. Undercut merupakan cacat pada bagian bawah logam induk yang tidak terisi karena penggunaan arus dan voltase yang terlalu tinggi, kecepatan pengelasan yang terlalu tinggi, penggunaan kawat las pengisi yang terlalu sedikit, dan kemiringan elektroda yang kurang tepat. Pembekuan tidak sempurna merupakan jenis cacat yang dikarenakan tidak terisinya kampuh las secara sempurna oleh kawat pengisi akibat dari penggunaan arus yang terlalu rendah, kecepatan pengelasan yang terlalu tinggi, geometri sambungan yang kurang tepat, dan diameter elektroda yang terlalu besar. Retak merupakan jenis cacat yang dapat terjadi tidak hanya pada deposit las melainkan juga pada logam induk khususnya pada daerah HAZ (heat affected zone) atau daerah terpengaruh panas. Jenisnya antara lain adalah, hydrogen induced cold cracking, lamellar tearing, liquation cracking, dan reheating cracking. Dalam rangka memperoleh jaminan kualitas hasil las maka setiap proses pengelasan harus mengikuti suatu standar operasi yang dituangkan dalam Welding Procedure Spesification (WPS) yang berisikan antara lain adalah proses, spesifikasi elektroda, karakteristik elektrik, spesifikasi logam induk, pemanasan awal, arus, voltase, kecepatan las, posisi pengelasan, perlakuan panas pasca las, gas pelindung, dan desain sambungan secara lengkap.

Pada setiap proses pengelasan, khususnya fusion welding, ada dua aspek yang terkait yaitu aspek termal dan aspek kimia. Aspek termal dapat mengakibatkan adanya perubahan pada material karena adanya siklus termal yang mengakibatkan terjadinya perubahan metalurgi seperti peleburan, transformasi fasa, tegangan sisa, dan distorsi. Penggunaan kawat las yang menyatu dengan logam yang dilas menyebabkan terjadinya perubahan kimia deposit las seperti pencampuran, pelarutan, dan penyerapan. Kedua aspek tersebut mempunyai hubungan yang sangat erat dengan sifat deposit las yang dihasilkan seperti sifat kimia, fisika, dan mekanik. Geometri lasan hasil fusion welding terdiri atas tiga bagian yaitu deposit las (weld metal), daerah terpengaruh panas (HAZ /heat affected zone), dan logam induk (base metal).

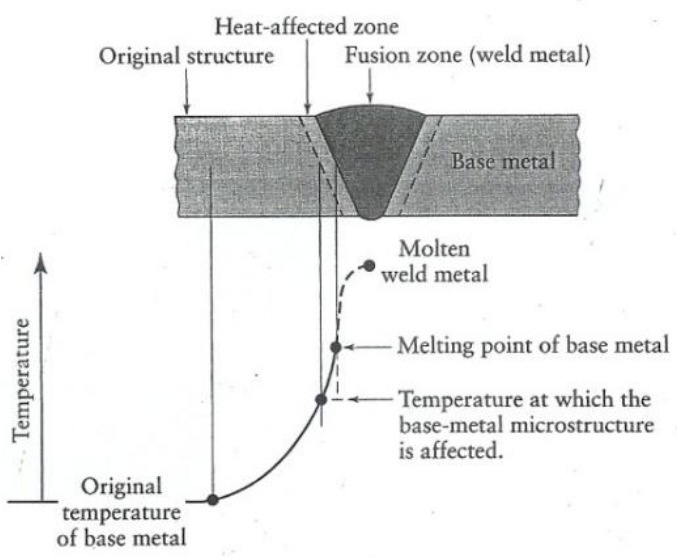

Gambar 1. Daerah-daerah pada logam las 
Tabel 1. Gas pelindung yang digunakan pada pengelasan

\begin{tabular}{|c|c|c|c|c|c|}
\hline Gas & $\begin{array}{c}\text { Chemical } \\
\text { Symbol }\end{array}$ & $\begin{array}{l}\text { Molecular } \\
\text { Weight } \\
\text { (g/mol) }\end{array}$ & $\begin{array}{l}\text { Specific Gravity } \\
\text { with respect to Air } \\
\text { at } 1 \mathrm{~atm} \text { and } 0^{\circ} \mathrm{C}\end{array}$ & $\begin{array}{c}\text { Density } \\
\text { (g/L) }\end{array}$ & $\begin{array}{c}\text { Ionization } \\
\text { Potential } \\
\text { (eV) }\end{array}$ \\
\hline Argon & $\mathrm{Ar}$ & 39.950 & 1.3800 & 1.784 & 15.7 \\
\hline Carbon Dioxide & $\mathrm{CO}_{2}$ & 44.010 & 1.5300 & 1.978 & 14.4 \\
\hline Helium & $\mathrm{He}$ & 4.000 & 0.1368 & 0.178 & 24.5 \\
\hline Hydrogen & $\mathrm{H}_{2}$ & 2.016 & 0.0695 & 0.090 & 13.5 \\
\hline Nitrogen & $\mathrm{N}_{2}$ & 28.010 & 0.9670 & 1.250 & 14.5 \\
\hline Oxygen & $\mathrm{O}_{2}$ & 32.000 & 1.1050 & 1.430 & 13.2 \\
\hline
\end{tabular}

Gas Tungsten Arc Welding (GTAW) disebut pula dengan proses las tungsten inert gas (TIG) merupakan proses pengelasan dimana busur listrik tercipta antara elektroda tungsten yang tak terumpan dan benda kerja. Daerah busur listrik diisi dengan gas inert (argon atau helium). Salah satu keunggulannya adalah logam pengisi dapat ditambahkan ke zona logam las secara terpisah dan tidak tergantung pada arus. Selain itu, proses pengelasan ini menghasilkan percikan yang rendah, tidak terdapat terak, dan mudah dibersihkan. Kelemahan utama proses GTAW terletak pada rendahnya kecepatan deposisi bahkan paling rendah dibandingkan dengan semua proses las. Hal ini dikarenakan proses GTAW menekankan pada kualitas logam las yang tinggi sehingga diperlukan arus yang rendah dan waktu las yang lebih lama. Juru las perlu mempelajari cara mengkoordinasi secara presisi pergerakan torch di satu sisi dan logam pengisi di sisi lainnya sambil mengontrol arus. Tungsten merupakan logam yang sangat keras dengan titik lebur $3400^{\circ} \mathrm{C}$ dan digunakan dalam keadaan murni atau paduan sebagai elektroda tak terumpan dalam las busur listrik. Arus yang digunakan pada proses las GTAW tergantung pada jenis elektroda yang digunakan, diameter elektroda, dan polaritas arus.

\section{Metode Penelitian}

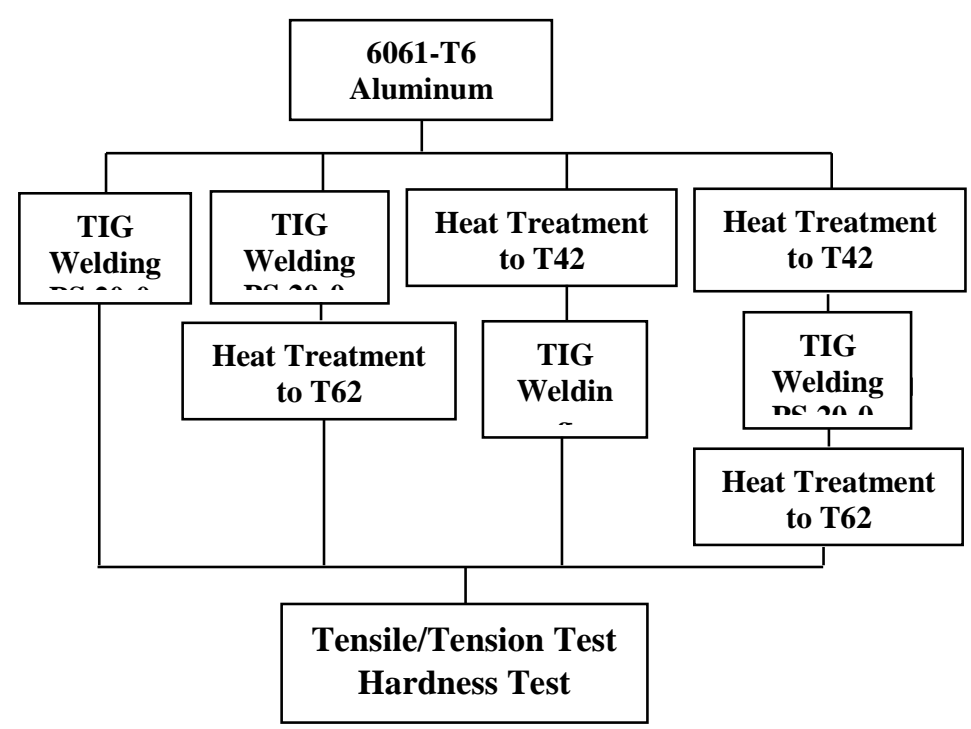

Gambar 2. Diagram alir penelitian 
Material teknik yang digunakan dalam penelitian ini adalah logam aluminium 6061 dengan spesifikasi QQ-A-250/11 yang merupakan logam aluminium dengan elemen paduan magnesium dan silikon. Standar pengujian menggunakan ASTM (American Society of Testing and Material).

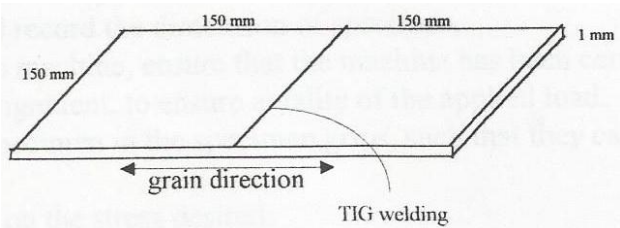

Gambar 3. Initial specimen geometry

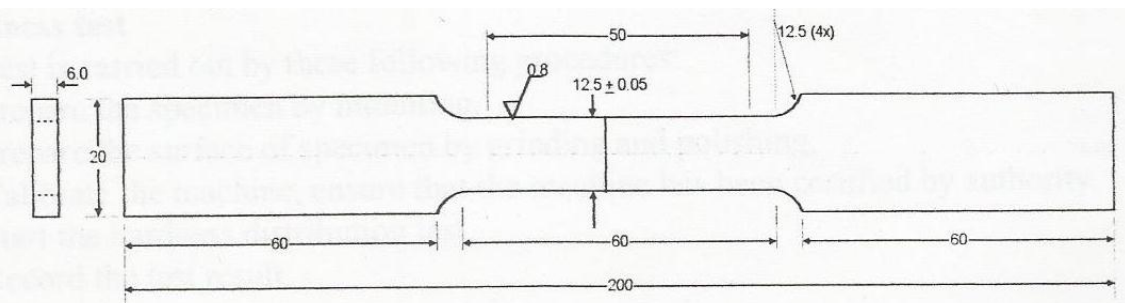

Gambar 4. Specimen geometry for tensile test (ASTM B 557M)

Gambar 5. Proses perlakuan panas

Proses pengelasan yang dilakukan adalah tungsten inert gas (TIG welding) atau GTAW (Gas Tungsten Arc Welding) menggunakan logam pengisi 4043 per AWS (American Welding Society) A5-10, proses perlakuan panas yang dilakukan adalah aging (precipitation hardening/strengthening).

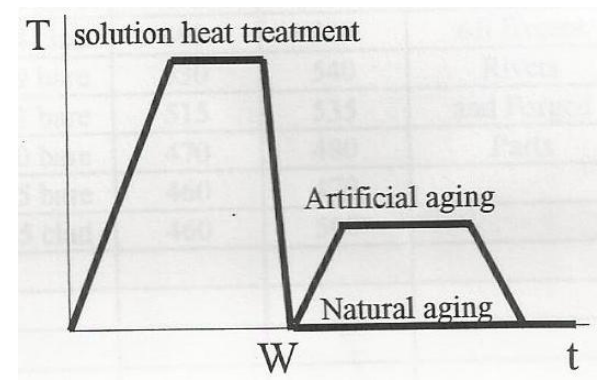

\section{Hasil dan pembahasan}

Kekuatan logam rata-rata setelah dilakukan proses pengelasan adalah 28,5 $\mathrm{Kgf} / \mathrm{mm}^{2}$ artinya logam ini mampu menahan beban hingga sebesar itu tanpa mengalami perpatahan (fracture), sedangkan kekuatan logam lasan setelah dilakukan proses perlakuan panas rata-rata meningkat menjadi $48,7 \mathrm{Kgf} / \mathrm{mm}^{2}$. Secara umum nilai kekerasan logam berbanding lurus dengan kekuatannya sehingga kekerasan logam lasan setelah dilakukan proses perlakuan panas juga meningkat.

Tabel 2. Hasil Uji Tarik dan Uji Keras

\begin{tabular}{|c|c|c|c|c|}
\hline \multirow{2}{*}{ Specimen } & \multicolumn{3}{|c|}{ Tensile/Tension Test } & \multirow{2}{*}{$\begin{array}{c}\text { Hardness Test } \\
\text { (HRE) }\end{array}$} \\
\cline { 2 - 4 } & $\begin{array}{c}\text { Tensile Strength } \\
\left(\mathrm{Kgf} / \mathbf{m m}^{\mathbf{2}}\right)\end{array}$ & $\begin{array}{c}\text { Yield Strength } \\
\left(\mathrm{Kgf} / \mathbf{m m}^{\mathbf{2}}\right)\end{array}$ & Strain (\%) & 71.9 \\
\hline $\mathbf{1}$ & 26.5 & 13.9 & 21.9 & 101.5 \\
\hline $\mathbf{2}$ & 48.5 & 39.9 & 8.5 & 88.1 \\
\hline $\mathbf{3}$ & 30.9 & 29.5 & 7.9 & 102.0 \\
\hline $\mathbf{4}$ & 48.9 & 39.9 & 8.1 & \\
\hline
\end{tabular}




\section{Kesimpulan}

Proses perlakuan panas artificial aging pada hasil proses pengelasan logam aluminium secara umum akan meningkatkan sifat mekanik. Perlu dilakukan pengujian mekanik pada aluminium hasil proses perlakuan panas natural aging untuk melihat pengaruhnya terhadap hasil proses pengelasan.

\section{Daftar Pustaka}

[1] Welding Processes and Practices, Leonard Koellhoffer, August Manz, \& Eugene Hornberger.

[2] Welding Metallurgy Volume 2, George Linert.

[3] Application of Modern Aluminum Alloys to Aircraft, Starke \& Staley.

[4] ASM Specialty Handbook, Aluminum and Aluminum Alloys.

[5] Heat Treatment, Structure, and Properties of Non-Ferrous Alloys, Charlie Brooks.
[6] Material Data of High-Strength Aluminum Alloys for Durability Evaluation of Structures, Schwarmann.

[7] Aluminum Alloys in The Aircraft Industry, Symposium

[8] Metals Handbook Volume 4,Heat Treating.

[9] Design of Weldments, Omer Blodgett.

[10] Welding Handbook Section 4, Metals and Their Weldability.

[11] Welding Metallurgy, Sindo Kou.

[12] ASM Handbook Volume 2, Properties and Selection: Nonferrous Alloys and SpecialPurpose.

[13] ASM Handbook Volume 8. Metallography, Structure, and Phase Diagrams. 